\title{
Application of advanced characterization techniques to assess DOM treatability of micro-polluted and un-polluted drinking source waters in China
}

\author{
Dongsheng Wang ${ }^{\mathrm{a}, *}$, Linan Xing ${ }^{\mathrm{a}}$, Jiankun Xie ${ }^{\mathrm{a}}$, Christopher W.K. Chow ${ }^{\mathrm{b}}$, Zhizhen Xu ${ }^{\mathrm{a}}$, Yanmei Zhao ${ }^{\mathrm{a}}$, \\ Mary Drikas ${ }^{b}$ \\ a State Key Laboratory of Environmental Aquatic Chemistry, Research Center for Eco-Environmental Sciences, Chinese Academy of Sciences, No. 18, Shuangqing Road, Haidian \\ District, Beijing 100085, China \\ ${ }^{\mathrm{b}}$ Australian Water Quality Centre, SA Water Corporation, 250 Victoria Square, Adelaide, SA 5000, Australia
}

\section{A R T I C L E I N F O}

\section{Article history:}

Received 11 May 2010

Received in revised form 9 July 2010

Accepted 9 July 2010

Available online 6 August 2010

\section{Keywords:}

DOM

Coagulation

HPSEC

Treatability

Modeling

\begin{abstract}
A B S T R A C T
China has a very complex water supply system which relies on many rivers and lakes. As the population and economic development increases, water quality is greatly impacted by anthropogenic processes. This seriously affects the character of the dissolved organic matter (DOM) and imposes operational challenges to the water treatment facilities in terms of process optimization. The aim of this investigation was to compare selected drinking water sources (raw) with different DOM character, and the respective treated waters after coagulation, using simple organic characterization techniques to obtain a better understanding of the impact of source water quality on water treatment. Results from the analyses of selected water samples showed that the dissolved organic carbon (DOC) of polluted waters is generally higher than that of un-polluted waters, but the specific UV absorbance value has the opposite trend. After resolving the high performance size exclusion chromatography (HPSEC) peak components of source waters using peak fitting, the twelve waters studied can be divided into two main groups (micro-polluted and un-polluted) by using cluster analysis. The DOM removal efficiency (treatability) of these waters has been compared using four coagulants. For water sources allocated to the un-polluted group, traditional coagulants $\left(\mathrm{Al}_{2}\left(\mathrm{SO}_{4}\right)_{3}\right.$ and $\left.\mathrm{FeCl}_{3}\right)$ achieved better removal. High performance poly aluminum chloride, a new type of composite coagulant, performed very well and more efficiently for polluted waters. After peak fitting the HPSEC chromatogram of each of the treated waters, average removal efficiency of the profiles can be calculated and these correspond well with DOC and UV removal. This provides a convenient tool to assess coagulation removal and coagulant selection.
\end{abstract}

(c) 2010 Elsevier Ltd. All rights reserved.

\section{Introduction}

Removal of dissolved organic matter (DOM) is still one of the major topics in water treatment technology research. DOM is heterogeneous, of low concentration, and poorly defined, and varies spatially and temporally. It includes all dissolved organic compounds, ranging from low molecular weight (MW) substances, such as amino acids and tannic acid, to high MW compounds, including humic substances, polysaccharides, proteins (Leenheer and Croue, 2003). Some compounds may promote the formation of harmful byproducts during chlorination of drinking water, and others may act as a substrate for undesired microbial growth in water distribution systems. In addition, DOM may foul membranes, block activated carbon pores and compete with taste and odor compounds for available adsorption sites, thereby reducing adsorption efficiency. It is crucial to understand the impact of

\footnotetext{
* Corresponding author. Tel./fax: +86 1062849138.

E-mail address: wgds@rcees.ac.cn (D. Wang).
}

DOM on water treatment processes by characterizing its physicochemical properties.

In order to understand DOM susceptibility to water treatment processes, finding simple and effective characterization methods is essential. Ultraviolet and fluorescence spectroscopy, solid state ${ }^{13} \mathrm{C}$ nuclear magnetic resonance spectroscopy, elemental analysis, and Py-GC-MS have been used to characterize DOM in a variety of surface waters (Wong et al., 2002; Leenheer and Croue, 2003; Abbt-Braun et al., 2004). However, these methods are more labor intensive and complex in sample preparation and analyses. Among the factors influencing the functionality of DOM and its susceptibility in water treatment processes, MW is one of the most important. Traditional approaches for MW determination of DOM include vapor pressure osmometry (VPO), low angle X-ray scattering, ultracentrifugation and flow field flow fractionation (FIFFF). High performance size exclusion chromatography (HPSEC), a simple but informative technique, is extensively used due to its small sample volumes, minimal amount of pretreatment, fast analysis time, availability of equipment, and the ability to determine 
both number-average and weight-average $\mathrm{MW}\left(M_{n}\right.$ and $M_{w}$, respectively). Pelekani et al. (1999) found good agreement, for different fractions measured, between FIFFF and HPSEC, within the technical limitations (such as solute gel interactions) of HPSEC; the validation of the technique with FIFFF indicates that HPSEC can provide reliable and useful MW distributions of DOM in drinking water supplies. Thus, HPSEC has become a popular tool to characterize DOM and predict DOM treatability (Zhou et al., 2000). It can be applied as a simple characterization method to optimize water treatment processes (O'Loughlin and Chin, 2001). Recently a peak fitting procedure to resolve HPSEC peaks and thus to provide quantitative information to predict DOM removal by coagulation was reported (Chow et al., 2008).

It is important to optimize coagulation processes with respect to DOM removal. The molecular size profile is useful for evaluating treatment processes and a key factor for controlling DOM reactivity (Yan et al., 2007; Li et al., 2008; Warton et al., 2008). Different DOM fractions exhibit different properties in terms of coagulation treatability. High MW DOM fractions tend to be more aromatic and possess higher electrostatic potential. They can be efficiently removed by coagulation and have lower coagulant demand due to the high charge density (Gang et al., 2003). Low MW fractions have small radii, tend to be more hydrophilic and some of them present negligible charge density. They are considered difficult to remove by coagulation (Sharp et al., 2006). Thus the low MW fractions can be applied as an indicator of the achievable DOC residual after coagulation and they also have a greater impact in terms of treated water quality and supply.

In this study, several drinking water sources (micro-polluted and un-polluted) in China were selected based on previous knowledge of DOM character. DOM removal efficiency of the source waters was compared using four coagulants. These were characterized to determine the impact of source water on water treatment processes. HPSEC, including peak fitting to resolve chromatographic components, was used to determine the coagulation treatability of DOM. The analytical information obtained will provide a basis for better design of the DOM removal process for different water sources in China. This information is essential for building a database linking water quality and DOM removal. This knowledge can be extended by using simple characterization methods for water treatment process optimization.

\section{Materials and methods}

\subsection{Materials}

All the reagents used were of analytical grade, except where otherwise specified. Four coagulants, $\mathrm{Al}_{2}\left(\mathrm{SO}_{4}\right)_{3}, \mathrm{FeCl}_{3}$, polyaluminum chloride (PACl) and a composite coagulant (HPAC), were used in this study. The coagulant, $\mathrm{PACl}(\mathrm{OH} / \mathrm{Al}$ molar ratio of 2.4), was prepared by the base titration method in the laboratory at room temperature (Wang et al., 2002). HPAC was produced by a local factory (Beijing Wanshui Water Cleaning Agent Co., China) using a technique developed in this laboratory.

$\mathrm{HPAC}$ is a new type of composite coagulant made from $\mathrm{PACl}$ with other organic and inorganic additives during the polymerization process. It was developed specifically for water with high alkalinity and $\mathrm{pH}$ values. The purpose of the new coagulant is to enhance both the charge neutralization and bridging ability of $\mathrm{PACl}$.

\subsection{Source waters}

In this study, 12 water samples were collected from nine sites to represent a good distribution of different levels of DOM in China.
The sampling sites are shown in Fig. 1. Sites 1, 4, 5, 6, 8 and 9 were selected from five large river systems (Songhua River, Luan River, Yellow River, Yangtze River and Pearl River) and sites 2, 3, 7 were selected to include several water supply reservoirs.

Water sample SH was taken from site 1 (Songhua River). Water sample TJ was from site 4 (Luan River). This river runs through industrial estates and residential areas in the north of China. Sites 5 and 6 are along the Yellow River, and samples ZZ and DY were collected from these two sites respectively. Three samples, NT, HP and YY, were taken from site 8 (downstream in the Yangtze River). Site 9 is located on the Pearl River (PW) and two samples, BJ and $\mathrm{XH}$, were collected from there.

In terms of general water quality for each river, the Pearl River and Yangtze River water quality is generally good, the Songhua River is slightly polluted, and the Yellow River is moderately polluted. However, when considering site specific conditions, samples $\mathrm{TJ}, \mathrm{ZZ}, \mathrm{HP}, \mathrm{XH}$, and SH are slightly contaminated due to the respective local manufacturing industries.

Three water samples were collected from three water supply reservoirs along the Songhua River and Yellow River (two samples), respectively. Water sample MP was taken from site 2 (a reservoir at Heilongjiang). Sample NB was collected from site 3 (south-to-north water diversion project). Sample ML was taken from site 8 (Yantai Menlou reservoir). The reservoir waters are relatively well protected and the water qualities were generally good.

Basic water quality parameters with polluted and non-polluted sites highlighted are shown in Table 1.

\subsection{Jar tests/treatment strategies}

All water samples have been kept at $4{ }^{\circ} \mathrm{C}$ during transportation and after arrival in our laboratory. The sampling program were carefully planned that both the jar test experiment and the measurement of the water quality parameters have been conducted as soon as the samples arrived in the laboratory. The coagulation $\mathrm{pH}$ was not controlled at the water plants, therefore to simulate

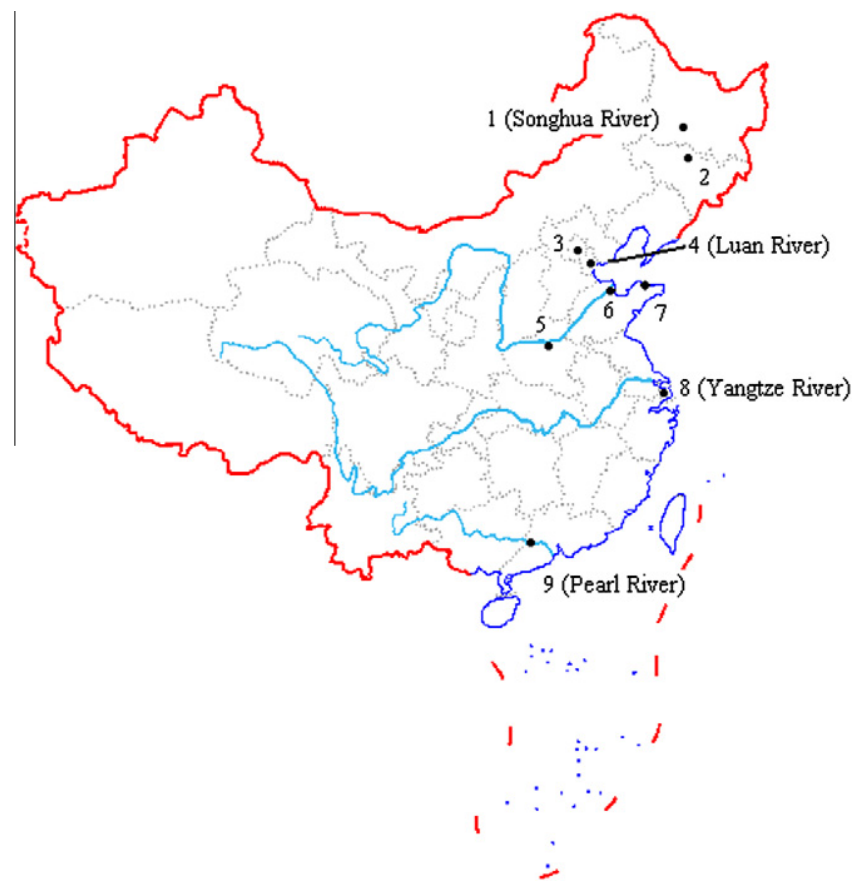

Fig. 1. Map of study area and sampling sites in China (sites 5, 6, and 7 are along the Yellow River). 
Table 1

Water quality parameters for selected raw drinking water sources in China, Autumn 2008 (Polluted samples are highlighted in gray.).

\begin{tabular}{|c|c|c|c|c|c|c|c|c|c|c|}
\hline Site & Sample & $\mathrm{pH}$ & Turbidity (NTU) & $\mathrm{UV}_{254}\left(\mathrm{~cm}^{-1}\right)$ & $\mathrm{DOC}\left(\mathrm{mg} \mathrm{L}^{-1}\right)$ & SUVA $\left(\mathrm{L} \mathrm{mg}^{-1} \mathrm{~m}^{-1}\right)$ & Alkalinity $\left(\mathrm{mg} \mathrm{L}^{-1}, \mathrm{CaCO}_{3}\right)$ & $M_{w}(\mathrm{Da})$ & $M_{n}(\mathrm{Da})$ & Polydispersity $(\rho)$ \\
\hline 1 & SH & 8.0 & 20.0 & 0.11 & 3.9 & 2.8 & 75 & 1746 & 1127 & 1.55 \\
\hline 2 & MP & 7.2 & 1.5 & 0.13 & 3.8 & 3.4 & 28 & 2449 & 1270 & 1.93 \\
\hline 3 & NB & 8.3 & 2.6 & 0.04 & 2 & 1.5 & 110 & 1327 & 831 & 1.6 \\
\hline 4 & $\mathrm{TJ}$ & 8.1 & 4.8 & 0.06 & 3.1 & 1.9 & 154 & 1301 & 809 & 1.61 \\
\hline 5 & $\mathrm{ZZ}$ & 8.1 & 6.8 & 0.05 & 2 & 2.5 & 168 & 1519 & 961 & 1.58 \\
\hline 6 & DY & 8.3 & 4.9 & 0.05 & 2.5 & 2.0 & 123 & 1365 & 859 & 1.59 \\
\hline 7 & ML & 8.0 & 1.2 & 0.06 & 2.4 & 2.5 & 103 & 1418 & 841 & 1.69 \\
\hline \multirow[t]{3}{*}{8} & NT & 8.0 & 95.0 & 0.05 & 1.2 & 4.2 & 85 & 1582 & 979 & 1.62 \\
\hline & HP & 7.4 & 92.5 & 0.1 & 3.9 & 2.6 & 73 & 1169 & 720 & 1.62 \\
\hline & $Y Y$ & 7.3 & 2.2 & 0.04 & 1.5 & 2.7 & 37 & 1278 & 790 & 1.62 \\
\hline \multirow[t]{2}{*}{9} & BJ & 7.2 & 7.6 & 0.04 & 0.9 & 4.4 & 65 & 1430 & 862 & 1.66 \\
\hline & $\mathrm{XH}$ & 7.0 & 49.0 & 0.09 & 3.1 & 2.9 & 55 & 1263 & 840 & 1.5 \\
\hline
\end{tabular}

the operation conditions, the jar tests were conducted without $\mathrm{pH}$ control.

Jar tests were performed on a programmable jar test apparatus (Daiyuan Jar Test Instruments, China). The operation procedure was as follows: $500 \mathrm{~mL}$ of raw water was transferred into a $600 \mathrm{~mL}$ square beaker; the jar tester was started at rapid mixing of $300 \mathrm{rpm}$ and, after $30 \mathrm{~s}$, coagulant was added followed by a reduction of the mixing speed to $250 \mathrm{rpm}$ for $2 \mathrm{~min}$; $40 \mathrm{rpm}$ for $10 \mathrm{~min}$ and then $20 \mathrm{~min}$ of quiescent settling. Four coagulants, $\mathrm{Al}_{2}\left(\mathrm{SO}_{4}\right)_{3}, \mathrm{FeCl}_{3}, \mathrm{PACl}$, and HPAC, were used in this study and six concentrations, $0.04,0.07,0.1,0.2,0.3$, and $0.4 \mathrm{mM}$, were dosed. $\mathrm{DOC}, \mathrm{UV}_{254}$, turbidity and $\mathrm{pH}$ were measured after the coagulation. Due to the variation of alkalinity in different water samples, to standardize the comparison, the selection of optimum dose was based on the DOC removal rate where the exponential curve (residual DOC versus dose) began to flatten out.

\subsection{Analytical methods}

DOC was analyzed by a TOC Analyzer (Phoenix 8000 system, Tekmar-Dohrman Co., USA) using the method of sodium peroxydisulphate/orthophosphoric acid wet oxidation and UV radiation after filtration through a $0.45 \mu \mathrm{m}$ membrane. The absorbance at $254 \mathrm{~nm}\left(\mathrm{UV}_{254}\right)$ was measured by a spectrophotometer (UV-Vis 8500 , China) using a $1 \mathrm{~cm}$ quartz cell after filtration through a $0.45 \mu \mathrm{m}$ membrane. Turbidity was measured using a $2100 \mathrm{~N}$ Turbidimeter (Hach, USA). pH was measured using a pHS-3C (Shanghai, China) $\mathrm{pH}$ meter, which was calibrated using $\mathrm{pH} 7.01$ and $\mathrm{pH} 9.18$ buffers.

A Waters liquid chromatography system consisting of the following components was used for the MW analysis: Waters 2487 Dual $\lambda$ Absorbance Detector, Waters 1525 pump system. Separation was performed with a Shodex KW 802.5 column (Shoko Co., Japan). The mobile phase, Milli Q water buffered with $5 \mathrm{mM}$ phosphate to $\mathrm{pH} 6.8$, and $0.01 \mathrm{M} \mathrm{NaCl}$, was filtered through a $0.22 \mu \mathrm{m}$ membrane, and then degassed for $30 \mathrm{~min}$. The flow rate was $0.8 \mathrm{~mL} \mathrm{~min}^{-1}$ and the injection volume was $200 \mu \mathrm{L}$.

Calibration standards for HPSEC should have the same molecular structure type as the sample (Conte and Piccolo, 1999; Egeberg and Alberts, 2003). Polystyrene sulphonate (PSS) were used as standards owing to their coiled configuration and appeared to be nearly identical to the aquatic humic substances (Allpike et al., 2005). It was confirmed by Cabaniss et al. (2000) that similar apparent molecular weight (AMW) results were obtained to those determined by VPO and FIFFF. Therefore PSS standards are more representative of DOM in their HPSEC characteristics (hydrodynamic radii, viscosity, etc.) than globular protein standards (Peuravuori and Pihlaja, 1997). The system was calibrated with PSS standards with MWs of 1.8, 4.2, 6.5, and $32 \mathrm{kDa}$ (Sigma-Aldrich,
USA), prepared at $1 \mathrm{~g} \mathrm{~L}^{-1}$ concentration. The PSS standards and acetone were detected at $230 \mathrm{~nm}$ and DOM samples at $254 \mathrm{~nm}$.

$M_{w}$ and $M_{n}$ of the DOM were determined using the following formulae (Zhou et al., 2000).

$M_{n}=\frac{\sum_{i=1}^{N} h_{i} M_{i}}{\sum_{i=1}^{N} h_{i}}$

$M_{w}=\frac{\sum_{i=1}^{N} h_{i} M_{i}^{2}}{\sum_{i=1}^{N} h_{i} M_{i}}$

$\rho=\frac{M_{w}}{M_{n}}$

where $h_{i}$ is the signal response amplitude of the HPSEC scan (sample) eluted at volume or at retention time; $M_{i}$, determined from the standard calibration curve, is the MW at eluted volume or at retention time. Polydispersity $(\rho)$ is the ratio of $M_{w}$ to $M_{n}$. When $M_{n}$ is equal to $M_{w}$, then $\rho$ indicates homogeneity of the sample and for a mixture of molecules, $M_{n}<M_{w}$ and $\rho>1$ (Zhou et al., 2000).

Considering the existence of a series of non-ideal interactions between the column stationary phase and solute, and the fact that the standards may not represent the true size of DOM molecules during analysis, the term "AMW" is used, rather than the terms "MW" or "molecular size" (Hoque et al., 2003). With MW calibration standards included in each batch of samples run, the obtained results are reproducible across the life of the column and show good consistency when compared with samples determined at different times.

Peak fitting software (Version 4, Systat Software Inc.) was used to resolve peak components based on statistically ideal fits using various peak shapes (Chow et al., 2008). The peak fitting parameters were chosen as per Chow et al. (2008). The DOM removal efficiency was calculated by using the difference between the peak area of the resolved peaks (after peak fitting) of raw and treated water from the HPSEC scans, for example, peak area of raw water Peak 1 - peak area of treated water Peak 1.

\section{Results and discussion}

\subsection{Source water quality}

\subsubsection{Geographical locations and water quality}

The surface water system in China consists of many rivers and lakes. The rivers generally flow from west to east and eventually to the Pacific Ocean. In this study, some of the world's largest rivers, namely the Yangtze River, Yellow River and Pearl River, were included. According to the 2008 national statement of the environmental situation in China, the Pearl River and Yangtze River water qualities are generally good; the Songhua River is slightly polluted 
with organic chemical products, such as detergents and pesticides; the Yellow River is moderately polluted: containing relatively high concentrations of ammonia, volatile phenol and PAHs, nitro chlorobenzenes and other organic compounds have been detected with relatively high concentration (MEP, 2009).

Table 1 summarizes the water quality parameters of the raw waters. In all cases the $\mathrm{pH}$ and DOC values decreased from north to south. Water sample SH was taken from the Songhua River which possesses high DOC and low SUVA value. Sample BJ was collected from the Pearl River. It is located in the south of China and its water has low alkalinity and $\mathrm{pH}$ and represents relatively good water quality in other respects (Chen, 2006). When considering samples collected from one river system, the DOC of polluted water is generally higher than that of un-polluted water but the SUVA value has an opposite trend. For example, sample HP (Yangtze River) was collected from an industrial area and its SUVA is lower than that of the two un-polluted water samples (NT and YY). In nonindustrial polluted waters, high MW humic substances are the main constituent and contribute to SUVA values. SUVA is proportional to the relative abundance of aromatic compounds and related functionalities in DOM. In terms of DOM reactivity and treatability, it can also be used as an evaluation parameter. Furthermore, high SUVA values indicate the likely presence of hydrophobic and high MW organic matter in the water (which can be removed by enhanced coagulation) while low SUVA values suggest that the water may be relatively hydrophilic in nature, possess lower MW components and be less responsive to enhanced coagulation (Wang, 2009).

\subsubsection{HPSEC and cluster analysis of raw waters}

HPSEC chromatographs have been processed by peak fitting software. Using the chromatograph of sample TJ as an example, the peak fitting result of AMW profiles is illustrated in Fig. 2. Five peaks were identified in the raw water DOM profile and the AMWs of the resolved peaks were calculated to be $2.7 \mathrm{kDa}$ (Peak 1), $1.8 \mathrm{kDa}$ (Peak 2), $1.2 \mathrm{kDa}$ (Peak 3), $500 \mathrm{Da}$ (Peak 4) and $300 \mathrm{Da}$ (Peak 5). The peak fitting results, of each AMW profile, are shown in Fig. 2. The higher AMW (Peaks 1 and 2) parts of the profiles, are much higher for samples SH and MP. Thus, these samples possess relatively high humic substance content. $\mathrm{SH}, \mathrm{TJ}, \mathrm{HP}, \mathrm{ZZ}$, and $\mathrm{XH}$ have a relatively higher portion of low AMW compounds (Peak 5) than other samples but these five also have higher DOC values.
This could be explained by the increasingly intense urban and industrial development around their watershed, resulting in runoff, sewage outfalls and discharge of wastewater from industrial areas. As discussed before, these contaminants have a high content of smaller organic compounds.

A graphical and statistical software package (SPSS 13.0) was applied to analyze the peak area of each resolved peak after peak fitting. The selected 12 waters were separated into two large groups according to similarity of distribution of AMW profiles. In Group 1, YY, BJ, NT, NB, DY and ML have similar AMW distributions and the corresponding locations are relatively well protected in terms of pollution control. Their portion of low MW compounds is small. In contrast, within Group 2, samples TJ and ZZ are slightly contaminated due to their respective local manufacturing industries. The other four samples in Group 2 (HP, XH, SH and MP) are contaminated by anthropogenic processes, and their ecological environments have been seriously damaged. Moreover, their proportion of low MW constituents is relatively high, which means that coagulation removal is expected to be less efficient.

\subsection{Coagulation treatability}

\subsubsection{Comparison of removal efficiency by the four coagulants}

The effectiveness of the four coagulants, $\mathrm{FeCl}_{3}, \mathrm{Al}_{2}\left(\mathrm{SO}_{4}\right)_{3}, \mathrm{PACl}$ and HPAC, on DOM removal has been reported to be different (Yan et al., 2008). However, no comprehensive study is available to allow an assessment as to which one is more efficient for DOM removal from a particular water source. In our research, the four coagulants were compared based on the optimum dose selection criteria stated in Section 2.3 and the results are shown in Fig. 3. UV removal occurred in the order $\mathrm{FeCl}_{3}>\mathrm{Al}_{2}\left(\mathrm{SO}_{4}\right)_{3}>\mathrm{PACl}$ and HPAC showed fluctuations in performance compared to the other three coagulants. HPAC showed the best $\mathrm{UV}_{254}$ removal for sample $\mathrm{ZZ}$, while it was the worst for TJ, YY, and $\mathrm{BJ}$. $\mathrm{FeCl}_{3}$ had good DOC removal while the other three coagulants were nearly the same, except that HPAC seemed slightly less effective. Although the effect of HPAC on DOC and UV removal was not consistently high compared with the others, the removal of SUVA was the highest of the four coagulants. Therefore HPAC has better removal of DOM fractions with relatively more prominent contributions of aromatic and related functionalities.

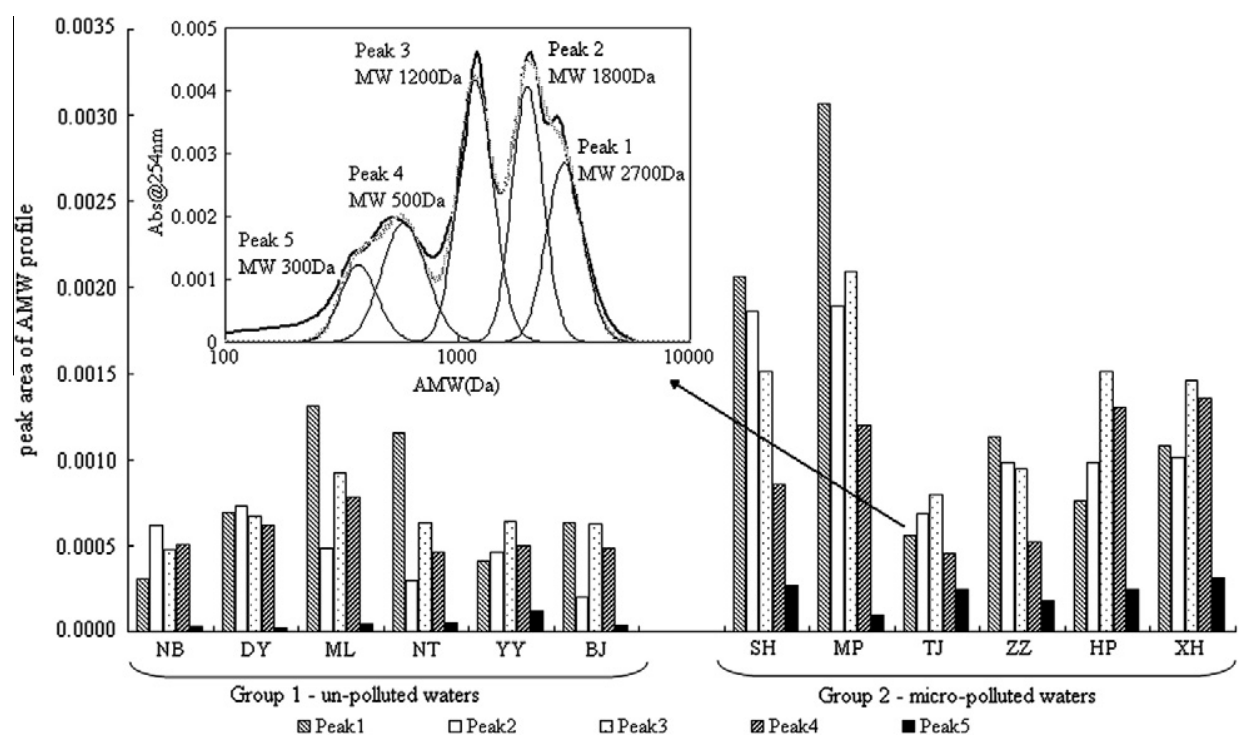

Fig. 2. AMW profiles in raw waters. Take one of the samples as an example of a peakfitting result, black line is observed, gray line is generated. 

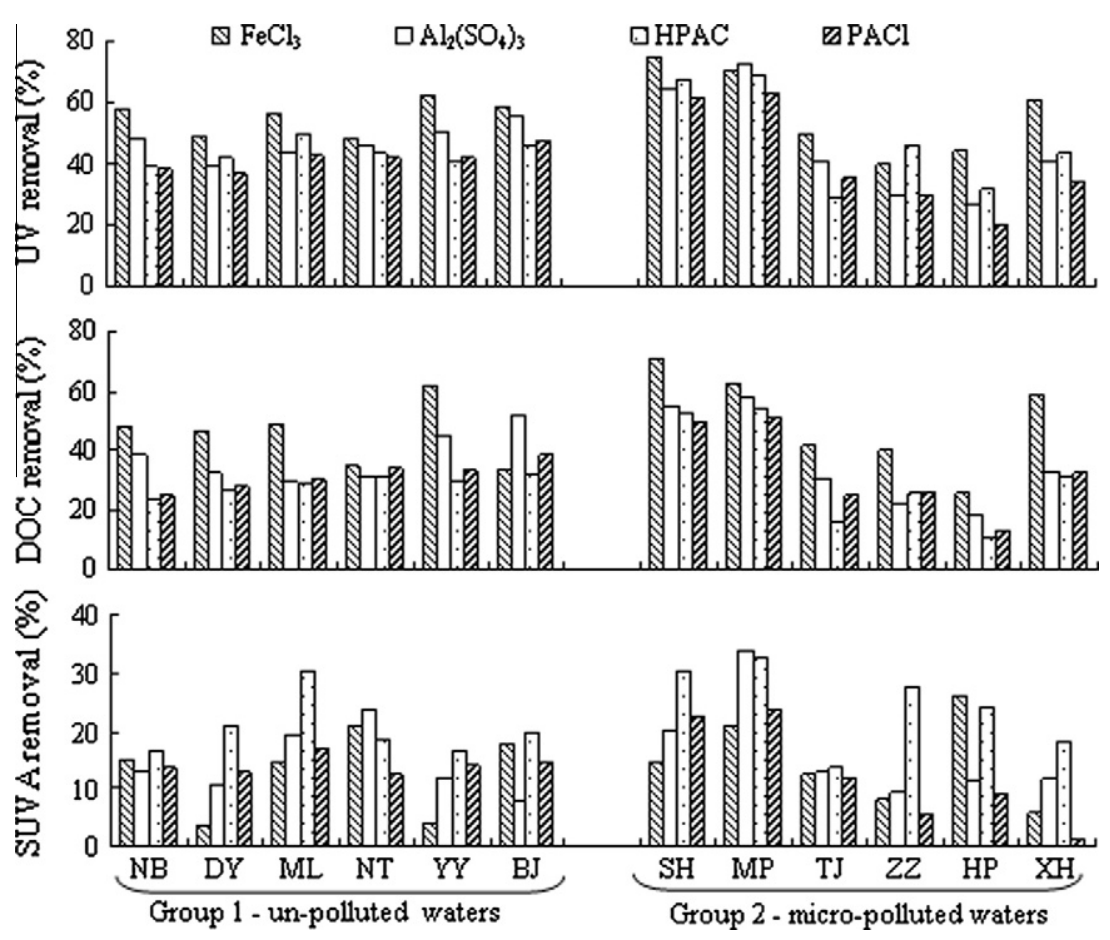

Fig. 3. Parameters of $\mathrm{UV}_{254}$, DOC and SUVA removal by coagulation treatment.

Table 2

Average removal efficiency of each component and standard deviation of the two raw water sets.

\begin{tabular}{|c|c|c|c|c|c|c|}
\hline \multirow[t]{2}{*}{ Coagulant } & \multirow[t]{2}{*}{ Water sets } & \multicolumn{5}{|c|}{ Calculated removal efficiency (\%) } \\
\hline & & Peak 1 & Peak 2 & Peak 3 & Peak 4 & Peak 5 \\
\hline \multirow[t]{2}{*}{$\mathrm{Al}_{2}\left(\mathrm{SO}_{4}\right)_{3}$} & Group 1 & $91 \pm 7$ & $28 \pm 20$ & $25 \pm 9$ & $11 \pm 8$ & $6 \pm 8$ \\
\hline & Group 2 & $97 \pm 3$ & $60 \pm 19$ & $35 \pm 15$ & $13 \pm 19$ & $34 \pm 19$ \\
\hline \multirow[t]{2}{*}{$\mathrm{FeCl}_{3}$} & Group 1 & $95 \pm 5$ & $54 \pm 18$ & $38 \pm 12$ & $23 \pm 8$ & $6 \pm 16$ \\
\hline & Group 2 & $99 \pm 2$ & $86 \pm 10$ & $60 \pm 9$ & $29 \pm 14$ & $39 \pm 17$ \\
\hline \multirow[t]{2}{*}{$\mathrm{PACl}$} & Group 1 & $87 \pm 9$ & $14 \pm 16$ & $18 \pm 10$ & $6 \pm 10$ & $13 \pm 10$ \\
\hline & Group 2 & $89 \pm 15$ & $44 \pm 17$ & $26 \pm 14$ & $12 \pm 19$ & $40 \pm 18$ \\
\hline \multirow[t]{2}{*}{ HPAC } & Group 1 & $90 \pm 7$ & $20 \pm 20$ & $19 \pm 6$ & $13 \pm 6$ & $13 \pm 17$ \\
\hline & Group 2 & $98 \pm 2$ & $60 \pm 17$ & $39 \pm 12$ & $24 \pm 16$ & $45 \pm 19$ \\
\hline
\end{tabular}

3.2.2. HPSEC character of organics being removed by each coagulant

In order to better understand the DOM removal characteristics of each coagulant, treated waters were analyzed by HPSEC and the percentage AMW distribution was determined by peak fitting. Table 2 presents the average removal efficiency of each component and the standard deviations obtained by calculating the percentage distribution before and after coagulation of the two groups of raw water determined by cluster analysis. All of the four coagulants removed Peak 1 (2.7 kDa) effectively, and the average removal efficiency was between $87 \%$ and $99 \%$. The DOM component is associated with chemical groups of biological residues and high MW humic substances. Peaks 2, 3 and 4 are associated with low MW humics and building blocks. Among the four coagulants, the removal efficiencies of the three peaks were higher for polluted waters (Group 2) than for the well-protected waters (Group 1). This is because the concentration of each peak component of the polluted waters was higher than in the well-protected waters, as shown in Fig. 2, and most of the humic substances could be well removed. In Cluster Group 1, the removal efficiency of the three peaks is in the order $\mathrm{FeCl}_{3}>\mathrm{Al}_{2}\left(\mathrm{SO}_{4}\right)_{3}>\mathrm{PACl}>\mathrm{HPAC}$. Cluster Group 2 follows $\mathrm{FeCl}_{3}>\mathrm{HPAC}>\mathrm{Al}_{2}\left(\mathrm{SO}_{4}\right)_{3}>\mathrm{PACl}$. The well-protected waters (Group 1) exhibit better removal when treated with traditional coagulants $\left(\mathrm{FeCl}_{3}\right.$ and $\left.\mathrm{Al}_{2}\left(\mathrm{SO}_{4}\right)_{3}\right)$. $\mathrm{FeCl}_{3}$ and $\mathrm{HPAC}$ can be applied to increase the removal of low MW compounds for the

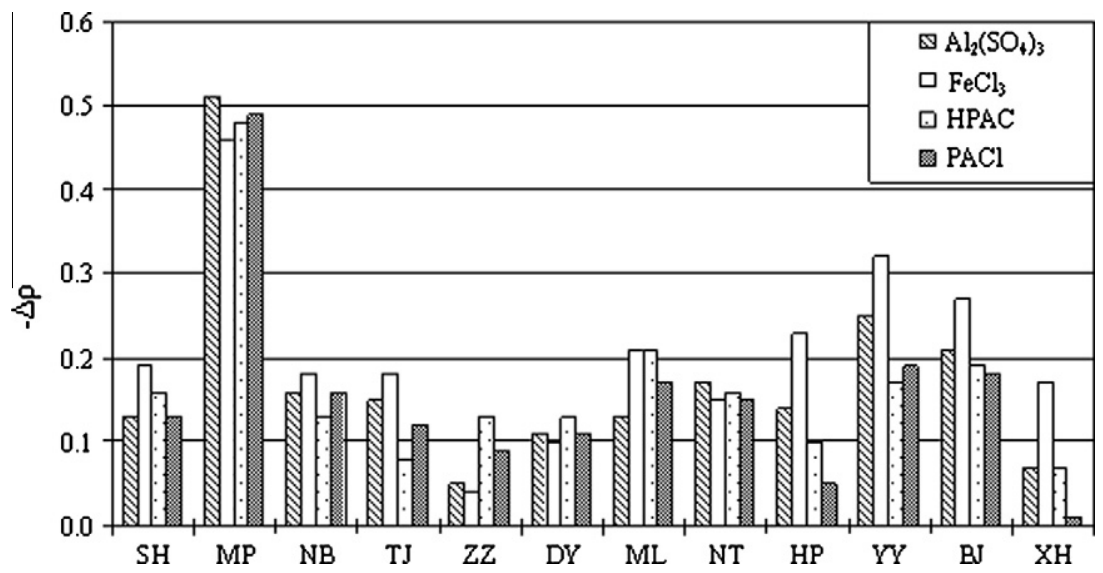

Fig. 4. $\Delta \rho$ of UV absorbing organic matter after treatment, determined by HPSEC. 

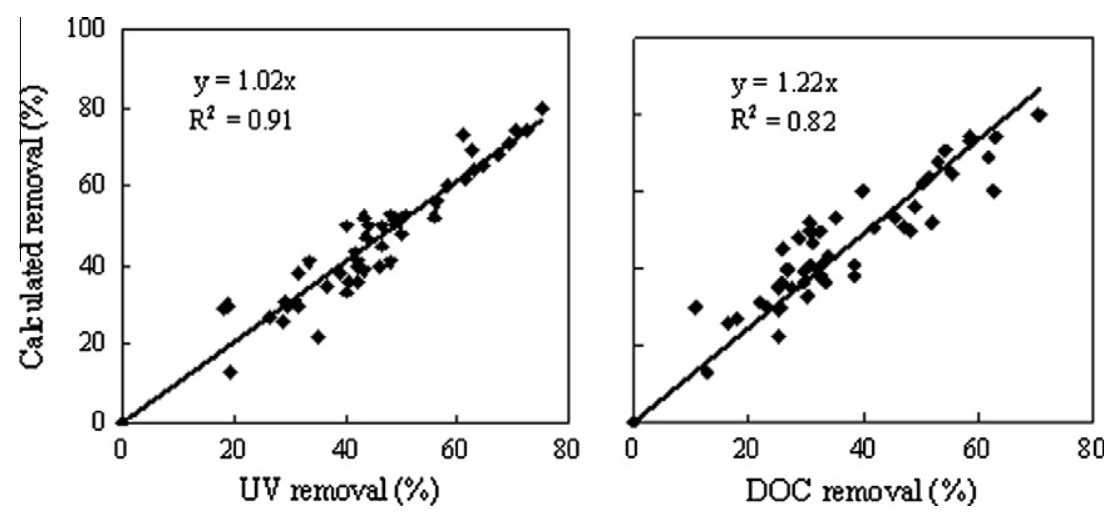

Fig. 5. Correlations of predicted AMW removal efficiency with secondary water quality parameters: $\mathrm{UV}_{254}$ and DOC removal efficiency.

polluted waters (Group 2). However, a high $\mathrm{FeCl}_{3}$ dose can increase the color of the treated waters. HPAC removed the low MW components (Peak 5) more than the other three coagulants. The aluminum species of HPAC remove contaminants following the mechanisms of complexation and adsorption.

The change in polydispersity $(\Delta \rho)$ after treatment indicates the effectiveness of the treatment and can also be seen as a measure of treatability of the water source (Fabris et al., 2008). The more that specific MW ranges are effectively removed, the more the $\rho$ changes. In Fig. 4, $\Delta \rho$ for the investigated water sources after treatment are presented. $\rho$ exhibited considerable change amongst all waters. The differences observed in treated water character could be attributed to source water character. $\Delta \rho$ 's of well-protected waters (Group 1) are slightly higher than those of polluted waters (Group 2), which means that coagulation is reducing the variation in $\mathrm{MW}$ of the organic material and hence the number of different compounds. For the polluted waters (Group 2), because of the relatively high proportion of low MW compounds, the number of different compounds did not reduce effectively.

The calculated DOM removal efficiency was obtained following the steps stated in Section 2.4. It was then compared with the actual removal of $U_{254}$ and of the DOC value. The calculated removal efficiency has a significant correlation with the actual $U_{254}$ and DOC removal efficiency (as shown in Fig. 5; $R^{2}$ reached 0.91 and 0.82 , respectively). This means that the HPSEC method can be used as an alternative technique to estimate the removal efficiency of $\mathrm{UV}_{254}$ and DOC.

\section{Conclusions}

Significant anthropogenic influences on source water quality in China associated with rapid economic progress have increased the complexity of aquatic organic matter removal. As a result, examination of the treatability of DOM has become the biggest challenge in water treatment. HPSEC is a relatively simple but informationrich technique to provide the DOM distribution before and after coagulation. The coagulation efficiency of different source waters either micro-polluted or well protected can be examined rapidly in terms of different components of the DOM. After peak fitting the HPSEC chromatogram of the treated waters, the average removal efficiency of the profiles can be calculated. The best removal of each of the different components can then be determined and the most appropriate coagulant recommended.

The $U_{254}$ removal corresponds better with the calculated efficiency than DOC removal, due to the UV detector adopted for HPSEC. However, it indicates also that some micro-components in DOC (not UV-detectable) might be removed during coagulation. To improve the model prediction, additional detectors in HPSEC would provide more useful information. Certain components that can be detected by HPSEC are difficult to remove through coagulation especially in the case of micro-polluted source waters. This would provide a useful tool for the optimization of water treatment processes by examining the combination of pre-ozonation, enhanced coagulation and advanced oxidation processes, etc. The average removal efficiency might also be predicted through this approach.

\section{Acknowledgements}

This work is supported by the NSF of China under 50921064, 50721006 and the national 863 program under 2006AA06Z312. This project is also supported by the special fund from the State Key Laboratory of Environmental Aquatic Chemistry, Project 08K08ESPCR. The authors are grateful for the kind support from the local water companies and colleagues which are too many to be able to list here.

\section{References}

Abbt-Braun, G., Lankes, U., Frimmel, F., 2004. Structural characterization of aquatic humic substances - the need for a multiple method approach. Aquat. Sci. 66, $151-170$.

Allpike, B.P., Heitz, A., Joll, C.A., Kagi, R.I. Abbt-Braun, G., Frimmel, F.H., Brinkmann, T., Her, N., Amy, G., 2005. Size exclusion chromatography to characterize DOC removal in drinking water treatment. Environ. Sci. Technol. 39 2334-2342.

Cabaniss, S.E., Zhou, Q., Maurice, P.A., Chin, Y.P., Aiken, G.R., 2000. A log-normal distribution model for the molecular weight of aquatic fulvic acids. Environ. Sci. Technol. 34, 1103-1109.

Chen, J.S., 2006. Principles of River Water Quality and River Water Quality in China. Science Press, Beijing, China.

Chow, C.W.K., Fabris, R., ven Leeuwen, J., Wang, D.S., Drikas, M., 2008. Assessing natural organic matter treatability using high performance size exclusion chromatography. Environ. Sci. Technol. 42, 6683-6689.

Conte, P., Piccolo, A., 1999. High pressure size exclusion chromatography (HPSEC) of humic substances: molecular sizes, analytical parameters, and column performance. Chemosphere 38, 517-528.

Egeberg, P.K., Alberts, J.J., 2003. HPSEC as a prepative fractionation technique for studies of natural organic matter (NOM). Environ. Technol. 24, 309-318.

Fabris, R., Chow, C.W.K., Drikas, M., Eikebrokk, B., 2008. Comparison of NOM character in selected Australian and Norwegian drinking waters. Water Res. 42 4188-4196.

Gang, D., Clevenger, T.E., Banerji, S.K., 2003. Relationship of chlorine decay and THMs formation to NOM size. J. Hazard. Mater. 96, 1-12.

Hoque, E., Wolf, M., Teichmann, G., Peller, E., Schimmack, W., Buckau, G., 2003. Influence of ionic strength and organic modifier concentrations on characterization of aquatic fulvic and humic acids by high-performance sizeexclusion chromatography. J. Chromatogr. A 1017, 97-105.

Leenheer, J., Croue, J., 2003. Characterizing aquatic dissolved organic matter Environ. Sci. Technol. 37, 18A-26A.

Li, F.S., Yuasa, A., Ando, Y., 2008. Characterization of micro-flocs of NOM coagulated by $\mathrm{PACl}$, alum and polysilicate-iron in terms of molecular weight and floc size. Water Sci. Technol. 57 (1), 83-90 
MEP, China; 2009. <http://www.zhb.gov.cn/plan/zkgb/2008zkgb/>.

O'Loughlin, E., Chin, Y.P., 2001. Effect of detector wavelength on the determination of the molecular weight of humic substances by high-pressure size exclusion chromatography. Water Res. 35, 333-338.

Pelekani, C. Newcombe, G., Snoeyink, V.L., Hepplewhite, C., Assemi, S., Beckett, R 1999. Characterization of natural organic matter using high performance size exclusion chromatography. Environ. Sci. Technol. 33, 2807-2813.

Peuravuori, J., Pihlaja, K., 1997. Molecular size distribution and spectroscopic properties of aquatic humic substances. Anal. Chim. Acta 337, 133-149.

Sharp, E.L., Parsons, S.A., Jefferson, B., 2006. Seasonal variations in natural organic matter and its impact on coagulation in water treatment. Sci. Total Environ. 363, 183-194.

Wang, D.S., 2009. Enhanced Coagulation Technologies Treat Micro-polluted Water. Science Press, Beijing, China.

Wang, D.S., Tang, H.X., Gregory, J., 2002. Relative importance of charge neutralization and precipitation on coagulation of kaolin with $\mathrm{PACl}$ : effect of sulfate ion. Environ. Sci. Technol. 36, 1815-1820.
Warton, B., Heitz, A., Allpike, B., Kagi, R., 2008. Size-exclusion chromatography with organic carbon detection using a mass spectrometer. J. Chromatogr. A 1207, 186-189.

Wong, S., Hanna, J.V., King, S., Carroll, T.J., Eldridge, R.J., Dixon, D.R., Bolto, B.A., Hesse, S., Abbt-Braun, G., Frimmel, F.H., 2002. Fractionation of natural organic matter in drinking water and characterization by ${ }^{13} \mathrm{C}$ cross-polarization magicangle spinning NMR spectroscopy and size exclusion chromatography. Environ. Sci. Technol. 36, 3497-3503.

Yan, M.Q., Wang, D.S., Shi, B.Y., Wang, M., Yan, Y., 2007. Effect of pre-ozonation on optimized coagulation of a typical North China source water. Chemosphere 69, 1695-1702.

Yan, M.Q., Wang, D.S., Yu, J.F., Ni, J.R., Edwards, M., Qu, J.H., 2008. Enhanced coagulation with polyaluminum chlorides: role of $\mathrm{pH} /$ alkalinity and speciation. Chemosphere 71, 1665-1673.

Zhou, Q., Cabaniss, S.E., Maurice, P.A., 2000. Considerations in the use of highpressure size exclusion chromatography (HPSEC) for determining molecular weights of aquatic humic substances. Water Res. 34, 3505-3514. 